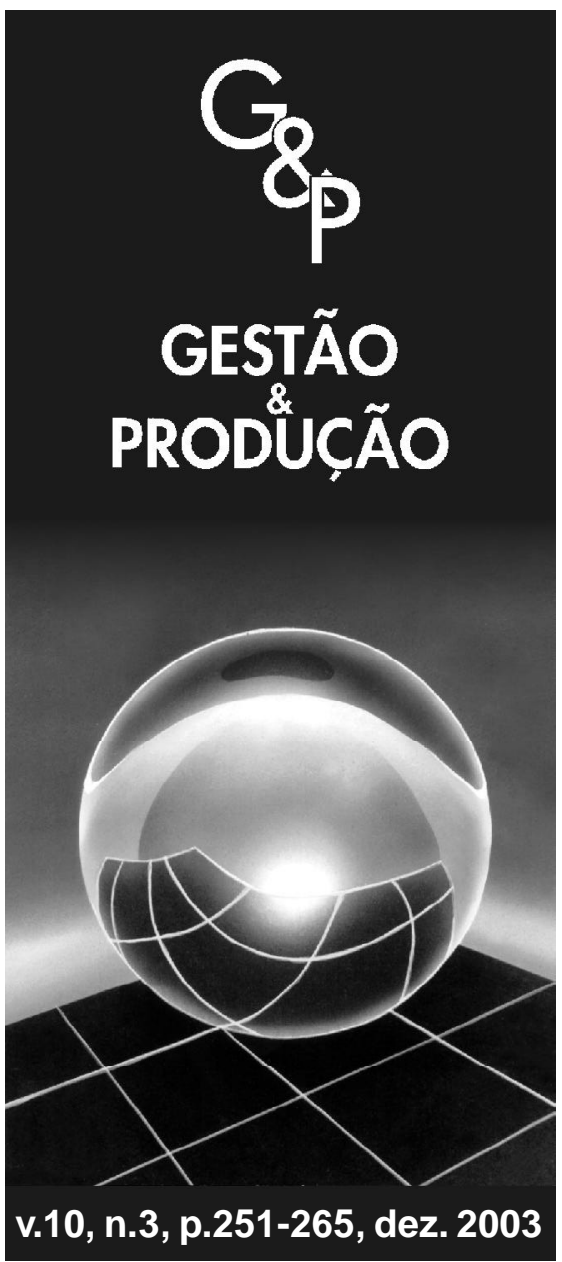

\title{
ESTRATÉGIAS DAS EMPRESAS DO SETOR CALCADISTA DIANTE DO NOVO AMBIENTE COMPETITIVO: ANÁLISE DE TRÊS CASOS
}

\author{
Andresa Silva Neto Francischini \\ Departamento de Engenharia de Produção, Universidade \\ Federal de São Carlos, C.P. 676, CEP 13565-905, São \\ Carlos, SP, e-mail: andnet@yahoo.com
}

Paulo Furquim de Azevedo

Departamento de Economia, Faculdade de Economia, Administração e Contabilidade de Ribeirão Preto (FEA-USP), Universidade de São Paulo, Avenida dos Bandeirantes, 3.900, Cidade Universitária, CEP 14021-520, Ribeirão Preto, SP, e-mail: pfa@usp.br

Recebido em 25/6/2003

Aceito em 26/11/2003

\section{Resumo}

O ambiente competitivo dos anos 90, marcado pelo processo de abertura comercial, pela adoção da Constituição de 1988, pela sobrevalorização cambial e pelas mudanças nos padrões de concorrência internacional, afetou de maneira diferenciada os setores industriais brasileiros. Este estudo avalia as estratégias tecnológicas, de localização e reorganizadoras adotadas por três empresas calçadistas diante desse novo ambiente competitivo da década de 1990. Esse conjunto de estratégias é avaliado segundo a formulação de quatro proposições, as quais mostram o impacto diferenciado do ambiente competitivo conforme as características das empresas estudadas.

Palavras-chave: ambiente competitivo, calçados, estratégia.

\section{Introdução}

$\mathrm{O}$ início da década de 1990 foi marcado por importantes mudanças no ambiente competitivo do qual participam as empresas brasileiras. Os os setores da indústria brasileira e as empresas que os compõem sentiram de forma diferenciada os impactos desse novo ambiente competitivo. Nele as empresas que fazem parte do setor calçadista passaram a adotar importantes estratégias de reestruturação e organização da produção como meio de manutenção da competitividade nos mercados nacional e internacional. 
Este estudo visa à identificação desse conjunto de estratégias, classificadas em três grandes grupos: estratégias tecnológicas, de localização e reorganizadoras. Para tanto, o artigo compara três estudos de caso de empresas calçadistas brasileiras, utilizando, na coleta de dados, entrevistas semi-estruturadas e análise de documentos e dados secundários. Trata-se de empresas de grande porte e que, portanto, definem estratégias compartilhadas por várias firmas que a elas se associam em redes de produção ou que as tomam como referência na definição de suas próprias estratégias. As três empresas também permitem comparações sobre os possíveis efeitos do novo ambiente competitivo, uma vez que atuam em segmentos diferentes nos mercados nacional e internacional, sendo, portanto, afetadas de modo distinto por eventos como abertura de mercado e sobrevalorização cambial durante o Plano Real. O estudo é guiado pela formulação de quatro proposições, que orientam a apresentação dos estudos de caso.

\section{Indústria de calçados: características gerais}

A indústria brasileira de calçados é formada por 6.346 estabelecimentos, responsáveis pelo emprego formal de 211.582 pessoas, segundo dados do Ministério do Trabalho e Emprego, relativos a 1999. Dada a presença de microempresas, com intensiva utilização de trabalho familiar, e a terceirização de atividades do processo produtivo, pode-se afirmar que o total de postos de trabalho diretos na indústria de calçados supera consideravelmente esse montante, uma vez que os dados da RAIS-MTE se restringem aos trabalhadores com carteira assinada. A capacidade produtiva da indústria de calçado é estimada em cerca de 600 milhões de pares de calçados/ano, dos quais $70 \%$ são destinados ao mercado interno e $30 \%$, à exportação. Vale notar que a demanda nacional é atendida quase totalmente por produtores locais, com pequeno volume de importações, cujo pico, no período de valorização do real, atingiu US\$ 200 milhões.

Tal atitude está presente em praticamente todos os Estados, com preponderância (mais de mil empregados) em 12 deles, destacam-se o Rio Grande do Sul - que concentra cerca de $40 \%$ da produção nacional de calçados e $80 \%$ das exportações totais - e São Paulo. Os Estados de Minas Gerais, Ceará, Paraíba, Bahia e Santa Catarina também apresentam importante produção de calçados.

No contexto mundial, a indústria brasileira ocupa posição de destaque: é a quarta maior produtora e o quinto maior mercado consumidor (Tabela 1). Sua importância nas exportações é maior do que sugere a tabela a seguir, em decorrência do fato de Hong Kong ser efetivamente um re-exportador de calçados. Estima-se que o Brasil seja o quinto maior exportador, com perspectivas de disputar a terceira colocação.

As exportações da indústria de calçados destacam-se na pauta de exportação brasileira, correspondendo, em 2000, a 2,94\% do total das exportações e a $5 \%$ do total das exportações de manufaturados.

Tabela 1 - Números do mercado mundial (1999) (em milhões de pares).

\begin{tabular}{|c|c|c|c|c|c|}
\hline \multicolumn{2}{|c|}{ Produtores } & \multicolumn{2}{|c|}{ Exportadores } & \multicolumn{2}{|c|}{ Consumidores } \\
\hline País & Quantidade & País & Quantidade & País & Quantidade \\
\hline$\overline{\text { China }}$ & 5.930 & China & 3.426 & China & 2.506 \\
\hline Índia & 700 & Hong Kong & 970 & EUA & 1.727 \\
\hline Indonésia & 507 & Itália & 347 & Índia & 657 \\
\hline Brasil & 499 & Vietnã & 221 & Japão & 557 \\
\hline Itália & 318 & Indonésia & 217 & Brasil & 375 \\
\hline
\end{tabular}

Fonte: SATRA (apud Azevedo \& Francischini, 2002). 
Com esse desempenho, o setor ocupou a quarta posição nas exportações de produtos manufaturados. As exportações de calçados são historicamente concentradas em poucos mercados consumidores, com destaque para os Estados Unidos, secundados de longe por alguns países da Europa - Reino Unido, Alemanha e Países Baixos -, pelo Canadá e, mais recentemente, por alguns vizinhos da América Latina, especialmente Argentina, Bolívia, Paraguai, Chile e Uruguai (Tabela 2). Essa característica torna a indústria brasileira mais vulnerável às flutuações econômicas de uma única economia, no caso a norteamericana. Tal problema torna-se mais evidente em um contexto de desaceleração da economia norte-americana como o ocorrido em 2001.

A vulnerabilidade externa da indústria de calçados não decorre de uma característica intrínseca do mercado, mas do relativo pouco desenvolvimento de funções gerenciais relevantes no Brasil. Uma vez que as atividades de design e gerenciamento de marca são atrofiadas na indústria brasileira, a colocação do produto depende dos interesses daqueles que desempenham essas funções. De modo geral, a produção brasileira recorre às competências norte-americanas e italianas para essas atividades, o que explica o viés de exportação para o primeiro país, em calçados, e o viés de cópia dos padrões impostos pelo segundo.

O Brasil é reconhecido como exportador de calçados de couro para passeio, preponderantemente para o segmento feminino, embora ocorram embarques de outros tipos, em menor volume (Tabela 3). É importante notar que esse segmento, em que o Brasil mais se destaca, é também aquele que apresenta maior preço médio por par exportado.

A abertura de mercado e a valorização do real entre 1994 e 1998 ocasionaram a transferência do padrão de concorrência do mercado internacional para o mercado interno, o qual passou a receber produtos provenientes do sudeste asiático. Assim, foram observadas alterações na estrutura produtiva de calçados e artigos de couro, com especial pressão à produção de bens de qualidade inferior, que, por sua vez, competiam diretamente com os baixos preços dos produtos importados.

O principal movimento da década, na área de desenvolvimento de produto, ressalta a passividade do setor em termos de marketing.

Tabela 2 - Exportações brasileiras de calçados por destino (2000).

\begin{tabular}{lcccc}
\hline \multicolumn{1}{c}{ Países } & $\begin{array}{c}\text { Valor } \\
\text { (milhões US\$) }\end{array}$ & $\%$ & $\begin{array}{c}\text { Pares } \\
\text { (milhões) }\end{array}$ & $\begin{array}{c}\text { Preço médio } \\
\text { (US\$/pares) }\end{array}$ \\
\hline EUA & 1.081 & 66,85 & 101 & 10,7 \\
Argentina & 129 & 7,98 & 23 & 5,61 \\
Reino Unido & 111 & 6,86 & 8 & 13,88 \\
Alemanha & 35 & 2,16 & 7 & 5 \\
Canadá & 34 & 2,1 & 4 & 8,5 \\
Chile & 22 & 1,36 & 3 & 7,33 \\
Paraguai & 21 & 1,3 & 8 & 2,63 \\
Bolívia & 18 & 1,11 & 3 & 6 \\
Países Baixos & 16 & 0,99 & 2 & 8 \\
Uruguai & 13 & 0,8 & 2 & 6,5 \\
Outros & 137 & 8,47 & 27 & 5,07 \\
TOTAL & 1.617 & 100 & 188 & 8,6 \\
(102 países) & & & & \\
\hline Font: SECEXMDIC & & & & \\
\hline
\end{tabular}

Fonte: SECEX/MDIC (apud Azevedo \& Francischini, 2002). 
Tabela 3 - Brasil: exportações de calçados por tipo (2000).

\begin{tabular}{lccccc}
\hline NCM & Tipo & $\begin{array}{c}\text { Valor } \\
\text { (mil US\$) }\end{array}$ & $\%$ & $\begin{array}{c}\text { Pares } \\
(\mathbf{m i l})\end{array}$ & $\begin{array}{c}\text { Preço médio } \\
\text { (US\$/ pares) }\end{array}$ \\
\hline 6403.99 .00 & Couro natural & 1.019 .958 & 66,41 & 98.945 & 10,31 \\
6403.91 .00 & Cobre tornozelo & 225.586 & 14,69 & 12.059 & 18,71 \\
6403.59 .00 & Outros couros & 77.762 & 5,06 & 4.808 & 16,17 \\
6404.20 .00 & Matéria têxtil & 7.066 & 0,46 & 581 & 12,16 \\
6402.99 .00 & Borracha/plástico & 93.031 & 6,06 & 15.016 & 6,20 \\
6402.20 .00 & Sandálias/tiras & 32.243 & 2,10 & 11.228 & 2,87 \\
6404.19 .00 & Matéria têxtil & 45.388 & 2,96 & 5.379 & 8,44 \\
6401.99 .00 & Borracha s/ costura & 9.926 & 0,65 & 7.226 & 1,37 \\
& Demais & 24.843 & 1,62 & 6.027 & 4,12 \\
6401 a 6405 & & 1.535 .803 & 100 & 161.269 & 9,52 \\
6406 & Partes de calçados & 70.451 & 4,59 & 25.143 & 2,80 \\
64 & TOTAL & 1.606 .254 & & 186.412 & 8,62 \\
\hline
\end{tabular}

Fonte: MDIC/SECEX (apud Azevedo \& Francischini, 2002).

Uma das principais vantagens comparativas brasileiras é a disponibilidade de matéria-prima a baixos custos, assim, o perfil da produção para exportação tem se voltado para produtos mais intensivos em matéria-prima e processamento. Nesse contexto, as atividades de design e marketing são relativamente menos exploradas (Azevedo, 2001).

No mesmo sentido, algumas das tecnologias de automação utilizadas na indústria de calçados e artefatos italiana, as quais deveriam ser reforçadas pela indústria brasileira, são o Computer Aided Design (CAD) e o Computer Aided Manufacturing (CAM). A automação traria muitos benefícios para a indústria, como redução das perdas do couro, aumento de sua qualidade, redução no uso de produtos químicos e redução e otimização do tratamento de efluentes (Azevedo \& Francischini, 2002). Além disso, tratase de importante estratégia para solucionar o problema de qualidade do couro brasileiro. $\mathrm{O}$ sistema de produção empregado na pecuária tem resultado em um couro com elevada incidência de defeitos, ocasionados principalmente por parasitas, cortes e outras marcas nos animais abatidos, somados ao fato de prevalecer no Brasil $\mathrm{o}$ abate de animais mais velhos. $\mathrm{O}$ couro brasi- leiro apresenta, ainda, maior porosidade e menor brilho quando comparado ao couro europeu, característica contrária ao Italian Look, que privilegia o brilho desse material.

\subsection{Indústria de calçados: um novo ambiente competitivo}

A década de 1990 marca uma profunda mudança no ambiente competitivo de que participam as empresas de calçados brasileiras, decorrente de mudanças institucionais, macroeconômicas e da concorrência internacional. Entre as principais mudanças institucionais destacam-se dois importantes fatos: o processo de abertura comercial e a Constituição de 1988.

De acordo com North (1994), o desempenho econômico é função das instituições e de sua evolução, uma vez que as instituições determinam os custos de transação, o ritmo de inovação tecnológica e, por conseqüência, os custos de produção. Desse modo, as instituições compreendem tanto as regras formais e as restrições informais (normas de comportamento, convenções e códigos de conduta auto-impostos) quanto os mecanismos responsáveis pela eficácia desses dois tipos de normas, sendo consideradas, portanto, as 
"regras do jogo", enquanto as organizações seriam os jogadores.

Nesse contexto, o processo de abertura comercial, iniciado no ano de 1988, pode ser considerado uma importante mudança institucional. A mudança nas "regras do jogo" pode ser verificada pela abolição de diversos regimes especiais de importação, pela redução da redundância tarifária e pela unificação da incidência de impostos sobre importação, além da redução de alíquotas, diminuindo também seu espectro. Do mesmo modo, a Constituição de 1988, entendida também como parte do processo de mudança institucional, levou, entre outros aspectos, à elevação do custo da mão-de-obra. Segundo Gremaud et al. (2002), a Constituição de 1988 trouxe, como principal dificuldade, o aumento das transferências de impostos para Estados e municípios, sem que fossem repassadas as obrigações, o que levaria à ampliação do desequilíbrio do orçamento federal. Ainda, a Constituição comprometeu o desenvolvimento de uma política industrial centralizada, uma vez que possibilitou aos Estados atuação mais agressiva pró-desenvolvimento, revelada na forma de guerra fiscal entre eles.

Entre as mudanças macroeconômicas que marcaram o novo ambiente competitivo em que atuavam as empresas brasileiras, destaca-se a sobrevalorização cambial. De acordo com Gremaud et al. (2002), a valorização da taxa de câmbio, combinada com o aquecimento da demanda no início dos anos 90 , possibilitou a ocorrência de déficts na balança comercial, causados pelo aumento significativo das importações, aliado ao fraco desempenho das exportações. Portanto, torna-se interessante avaliar o comportamento das empresas pertencentes ao setor calçadista nesse novo ambiente competitivo, já que por ser um setor exportador, foi um dos mais fortemente afetados pela sobrevalorização cambial (Garcia, 2001; Gorini \& Siqueira, 1998). O efeito dessas mudanças institucionais, entretanto, não deve ter sido generalizado, uma vez que há empresas mais dependentes do mercado externo ou que produzem produtos mais suscetíveis à concorrência dos importados. Por conta disso, apresenta-se, a seguir, a primeira proposição que orienta a análise dos estudos de caso.

P1. "As empresas calçadistas foram afetadas, em graus diferenciados, pelo processo de abertura comercial e pela sobrevalorização cambial, de acordo com o segmento em que atuam."

Ainda considerando as mudanças nos padrões de concorrência internacional, as empresas pertencentes ao setor calçadista sofreram um estreitamento de seus espaços de atuação, explicado principalmente por dois fatos: a) elevação da qualidade de calçados chineses; e b) redução dos custos de produção da Itália.

As empresas calçadistas brasileiras enfrentaram redução em seus volumes de exportação de calçados femininos de couro pelo acirramento da concorrência trazido pelos calçados chineses. A participação brasileira no valor total importado pelos Estados Unidos - responsável pela absorção de $67 \%$ das exportações brasileiras de calçados em 2000 - vem caindo expressivamente nos últimos anos. Assim, de uma participação, em média, de $11 \%$ no período de 1990 a 1993, o calçado brasileiro caiu para menos de $7 \%$ em 1998, enquanto no mesmo período o mercado cresceu cerca de $50 \%$. Nesse mesmo intervalo, os embarques da China, em contrapartida, subi ram de $16 \%$ para $60 \%$ do valor total importado. Essa cifra é ainda mais expressiva quando se considera a participação chinesa no volume importado, que atinge $80 \%$ do total, o que decorre do menor preço médio obtido pelo calçado chinês.

É notável também a elevação da participação de produtos chineses nas importações brasileiras de calçados, em especial no segmento de tênis e de injetados. De acordo com dados do Ministério do Desenvolvimento (2002), em 1995, a China, juntamente com Argentina e Indonésia, contribuiu com $67 \%$ das importações brasileiras de calçados.

Enquanto no segmento de calçados de custos inferiores o Brasil enfrenta a concorrência crescente da China, no segmento high-end de calçados, a Itália vem obtendo reduções de custos 
de produção, fazendo frente à concorrência brasileira. Considerada forte concorrente do Brasil no mercado internacional, a Itália tem adotado a estratégia de terceirização de sua produção de calçados em países que apresentam menores custos de mão-de-obra, particularmente em países do Leste Europeu. Ainda, procura divulgar suas marcas próprias nos grandes eventos internacionais do setor e a maioria das exportações é efetuada sob encomenda (Gorini, 1998).

Desse modo, as modificações nos padrões de concorrência internacional tiveram impactos sobre as estratégias formuladas, nesse novo ambiente competitivo, pelas empresas calçadistas brasileiras. Coutinho (1993) ressalta que, entre as tendências gerais do complexo têxtil, composto pelas indústrias de vestuário, calçados e têxtil, a nova tendência mundial foi a produção em pequenos lotes, considerando as novas exigências de moda e estilo, que enfocavam a importância do design. Esse cenário exigiu das empresas a capacidade de organizar a produção de forma mais flexível, por meio de respostas rápidas diante de mudanças nos padrões de demanda. Do mesmo modo, Garcia (1996) destaca a notável elevação do conteúdo tecnológico de produtos e a sofisticação, principalmente, no design dos produtos de vestuário e dos calçados.

Portanto, essas mudanças no ambiente competitivo podem ser consideradas responsáveis pelo fato de as três empresas abordadas neste estudo terem adotado algumas estratégias, representando um meio de manutenção da competitividade. Esse conjunto de estratégias passa, então, a ser dividido em três importantes grupos: estratégias tecnológicas, de localização e reorganizadoras.

\section{Estratégias tecnológicas}

Como estratégia tecnológica consideram-se, de acordo com Alves Filho (1991), os esforços e as ações de uma empresa no sentido de ampliar sua capacidade tecnológica, considerando tanto as atividades de $\mathrm{P} \& \mathrm{D}$ como o projeto do produto, de processos e fabricação, e de gestão da produção. Por sua vez, a formulação e a implementação de uma estratégia tecnológica requer o estudo das condições do ambiente e das condições internas da empresa, a especificação de direções e objetivos de desenvolvimento, além da determinação das atividades a serem desenvolvidas para ampliar a capacidade tecnológica e implementar mudanças técnicas. Considerando que as alterações no ambiente competitivo devem afetar a formulação e a implementação de estratégias tecnológicas por parte das empresas, apresentase, a seguir, a segunda proposição a ser investigada nos estudos de caso.

P2. "O novo ambiente competitivo exigiu das empresas a capacidade de adotar estratégias tecnológicas com o objetivo de ampliarem suas capacidades tecnológicas."

\section{Estratégias de relocalização}

As alterações no ambiente competitivo também tiveram efeito sobre as decisões locacionais das empresas. Esse tipo de estratégia pode ser identificado como a transferência de unidades produtivas de um Estado para outro a partir de vantagens, para as empresas, possibilitadas pela Constituição de 1988.

De acordo com Garcia (2001), entre as empresas do setor calçadista houve clara tendência de relocalização de unidades produtivas para a região Nordeste do País, especialmente para os Estados do Ceará e Bahia. Segundo esse autor, entre os anos de 1990 e 1996 houve aumento de $200 \%$ no total de empregos gerados pela indústria calçadista no Nordeste, particularmente no Ceará.

O principal objetivo das empresas, que têm estabelecido unidades industriais principalmente na região Nordeste, é buscar menores custos de produção. Segundo Azevedo \& Toneto (2001), essa redução de custos se dá em várias frentes. A primeira delas refere-se aos custos do trabalho, ou seja, aos provenientes do pagamento de salários aos trabalhadores. Na região Nordeste, esses custos são significativamente menores do que os custos verificados nas regiões tradicionais. Considerando apenas o Estado do Ceará, verificou-se que $88 \%$ dos trabalhadores da indústria calçadista tinham renda média inferior a dois 
salários mínimos, enquanto nos Estados de São Paulo e Rio Grande do Sul esse porcentual passava para $29 \%$ e $34 \%$, respectivamente. Esta disparidade de salários entre as regiões brasileiras pode ser evidenciada na Tabela 4. Por outro lado, esses dados também revelam que não é somente o nível de salários que explica as estratégias de relocalização. Estados como Piauí apresentam salários ainda mais baixos, não sendo, porém, capazes de atrair as empresas calçadistas. Como será visto a seguir, os incentivos fiscais tiveram papel central nesse processo de relocalização.

As empresas que se têm instalado na região Nordeste contam com diversos benefícios fiscais, pela concessão de incentivos dos governos estaduais, e creditícios, especialmente por meio de recursos da Superintendência para o Desenvolvimento do Nordeste (Sudene). As vantagens de custo que uma empresa obtém para produzir na região Nordeste podem ser avaliadas em torno de $16 \%$ em relação à região do Vale dos Sinos (Costa \& Flingespan, 1997, apud Garcia, 2001).

As regiões Sul e Sudeste, entretanto, não deixaram de ter participação importante na produção e na geração de emprego no setor. Especialmente no caso da região Sudeste, essa participação tem sofrido reduções graduais. Além disso, as em- presas que têm estabelecido unidades fabris no Nordeste transferiram para essa região apenas parte do processo produtivo, mantendo nas regiões tradicionais a produção de linhas de produtos mais sofisticados. Somando-se a esse fato, outras atividades relacionadas ao processo de produção como o gerenciamento da atividade produtiva, a concepção e as atividades de design dos calçados e de desenvolvimento de produtos - também têm sido mantidas nas regiões tradicionais. Dessa maneira, as regiões tradicionais apresentam elevada importância para a indústria calçadista, uma vez que o locus da acumulação industrial não foi deslocado.

Os dados da RAIS-TEM (Tabela 5) revelam importantes características do movimento de relocalização, como a perda de participação do Rio Grande do Sul e São Paulo - embora ainda liderem folgadamente a lista dos principais empregadores. Os setores mais sujeitos à relocalização são os de calçados de plástico e de outros materiais, nos quais as vantagens comparativas dos pólos do Vale dos Sinos e de Franca são menores. Além disso, a relocalização tem sido mais adotada pelas grandes empresas, o que implicou maior tamanho médio de empresas nos Estados da região Nordeste.

Tabela 4 - Salários pagos na indústria calçadista brasileira - Estados selecionados (média brasileira $=1$ ).

\begin{tabular}{lcc}
\hline \multicolumn{1}{c}{ Estados } & $\mathbf{1 9 8 6}$ & $\mathbf{1 9 9 8}$ \\
\hline Piauí & 0,43 & 0,49 \\
Ceará & 0,60 & 0,76 \\
Paraíba & 0,65 & 0,81 \\
Pernambuco & 0,95 & 1,22 \\
Bahia & 0,54 & 0,63 \\
Minas Gerais & 0,73 & 0,71 \\
Rio de Janeiro & 0,80 & 1,15 \\
São Paulo & 1,09 & 1,13 \\
Paraná & 0,68 & 0,75 \\
Santa Catarina & 0,67 & 0,73 \\
Rio Grande do Sul & 1,05 & 1,08 \\
Goiás & 0,52 & 0,55 \\
\hline
\end{tabular}

Fonte: Azevedo \& Toneto (2001). 
Portanto, há sinais de que os novos pólos de produção são bastante diferentes dos antigos, seja em perfil de produto, seja em perfil de empresa.

Essa diferente configuração da indústria nordestina pode decorrer do fato de as grandes empresas mostrarem-se mais sensíveis às políticas de incentivo fiscal - principal justificativa para relocalização das empresas. Essa relação sustentase em dois argumentos não mutuamente excludentes. Primeiro, a obtenção de incentivos fiscais depende do domínio de informação relevante e da capacidade de negociação, elementos fortemente sujeitos a economias de escala. Segundo, grandes empreendimentos são proporcionalmente mais visíveis, de tal modo que a renúncia fiscal para atrair uma grande empresa pode traduzir-se em maior número de votos ao governante. Como conseqüência, eles têm mais interesse em conceder favores fiscais às empresas de maior porte. Assim, explica-se por que o perfil das empresas operantes no Nordeste, região que tem implementado políticas regionais de atração de investimentos no setor calçadista, é de grande porte.

Diante das informações obtidas pelas fontes secundárias, apresenta-se, a seguir, a terceira proposição que orienta a análise dos três casos de empresa.

P3. "A relocalização das unidades de produção para o Nordeste é importante estratégia de redução dos custos de produção adotada pelas empresas calçadistas, explicada principalmente pelo baixo custo da mão-deobra e pelos incentivos fiscais. Essa estratégia é entendida como fundamental para sobrevivência no novo ambiente competitivo, sobretudo como meio de redução de custos."

Tabela 5 - Brasil: número de empregos segundo segmentos da indústria de calçados e estabelecimentos por Unidade da Federação - 1999.

\begin{tabular}{|c|c|c|c|c|c|c|c|c|}
\hline \multirow{2}{*}{$\begin{array}{l}\text { Unidade da } \\
\text { Federação }\end{array}$} & \multicolumn{5}{|c|}{$\begin{array}{l}\text { № de empregos formais nos ramos da } \\
\text { indústria de calçados }\end{array}$} & \multirow{2}{*}{$\begin{array}{c}\text { \% no } \\
\text { emprego }\end{array}$} & \multirow{2}{*}{$\begin{array}{l}\text { Estabeleci- } \\
\text { mentos }\end{array}$} & \multirow{2}{*}{$\begin{array}{l}\text { № médio de } \\
\text { empregados por } \\
\text { estabelecimento }\end{array}$} \\
\hline & Couro & Tênis & Plástico & $\begin{array}{l}\text { Outros } \\
\text { materiais }\end{array}$ & Total & & & \\
\hline $\begin{array}{l}\text { Rio Grande } \\
\text { do Sul }\end{array}$ & 97.006 & 2.524 & 905 & 7.199 & 107.634 & 51,62 & 2.119 & 50,79 \\
\hline São Paulo & 22.850 & 6.556 & 3.104 & 8.556 & 41.066 & 19,69 & 1.899 & 21,63 \\
\hline Ceará & 8.864 & 22 & 10.864 & 1.234 & 20.984 & 10,06 & 162 & 129,53 \\
\hline Minas Gerais & 6.231 & 3.414 & 117 & 3.981 & 13.743 & 6,59 & 1.166 & 11,79 \\
\hline Paraíba & 1.047 & 1.611 & 94 & 4.949 & 7.701 & 3,69 & 85 & 90,60 \\
\hline $\begin{array}{l}\text { Santa } \\
\text { Catarina }\end{array}$ & 2.839 & 6 & 0 & 373 & 3.218 & 1,54 & 226 & 14,24 \\
\hline Pernambuco & 402 & 0 & 32 & 1.876 & 2.310 & 1,11 & 32 & 72,19 \\
\hline Bahia & 4.728 & 30 & 47 & 160 & 4.965 & 2,38 & 71 & 69,93 \\
\hline $\begin{array}{l}\text { Espírito } \\
\text { Santo }\end{array}$ & 373 & 486 & 0 & 574 & 1.433 & 0,69 & 37 & 38,73 \\
\hline Paraná & 853 & 12 & 5 & 293 & 1.163 & 0,56 & 159 & 7,31 \\
\hline $\begin{array}{l}\text { Rio de } \\
\text { Janeiro }\end{array}$ & 369 & 11 & 5 & 651 & 1.036 & 0,50 & 88 & 11,77 \\
\hline $\begin{array}{l}\text { Rio Grande } \\
\text { do Norte }\end{array}$ & 1.282 & 0 & 16 & 3 & 1.301 & 0,62 & 15 & 86,73 \\
\hline Goiás & 632 & 0 & 4 & 119 & 755 & 0,36 & 112 & 6,74 \\
\hline Sergipe & 710 & 0 & 0 & 0 & 710 & 0,34 & 9 & 78,89 \\
\hline Outros & 294 & 26 & 133 & 38 & 491 & 0,24 & 73 & 6,73 \\
\hline TOTAL & 148.480 & 14.698 & 15.326 & 30.006 & 208.510 & 100,0 & 6.253 & 33,35 \\
\hline
\end{tabular}

Fonte: RAIS-TEM (apud Azevedo \& Francischini, 2002). 


\section{Estratégias reorganizadoras}

Finalmente, o novo ambiente competitivo levou as empresas a adotar estratégias de produção que, genericamente, "são abordagens comuns para organizar a função produção que têm sido observadas por serem adotadas em diferentes tipos de organizações" (Slack et al., 1997). Desse modo, uma revisão das estratégias de produção de diversas organizações evidencia que as estratégias adotadas por organizações individuais podem ser agrupadas em termos de estratégias similares ou por elementos comuns.

Entre as estratégias de produção, esses autores destacam a "Estratégia Reorganizadora". Sua adoção implica mudança na maneira pela qual a organização desenha e administra seus processos e, o que é mais importante, uma forma diferente de organizar seus métodos de produção de bens e serviços.

No conjunto de estratégias reorganizadoras adotadas pelas empresas calçadistas, destacamse aspectos ligados à comercialização de seus produtos e à tendência a maior segmentação e especialização. Em particular, a década de 1990 marcou um processo de terceirização - freqüientemente acompanhado de precarização das relações de trabalho - e introdução de novos sistemas de produção na indústria de calçados, que possibilitam reduzir custos de produção, seja pela redução de encargos trabalhistas, seja pela maior velocidade de resposta às mudanças na demanda por calçados (Garcia, 2001). Diante disso, apresenta-se, a seguir, a quarta proposição que orienta a análise dos estudos de caso.

P4. "A adoção de estratégias como a terceirização das atividades e a introdução de novos sistemas de produção surgiu em resposta ao novo ambiente competitivo. $O$ objetivo é reduzir os custos de produção e ganhar velocidade de resposta às modificações da demanda."

\section{Apresentação dos estudos de casos}

Conforme definido anteriormente, são consideradas três empresas calçadistas neste estudo. Essas são denominadas empresas A, B e C, e suas principais características são apresentadas a seguir.

A Empresa A pertence a um dos maiores grupos de fabricantes de calçados plásticos no Brasil, tendo cerca de 16 mil funcionários empregados. Seu complexo industrial encontra-se dividido entre os Estados do Rio Grande do Sul (três unidades) e Ceará (nove unidades). Não há participações em atividades correlatas, portanto, não há integração vertical. Sua produção anual é de cerca de 80 milhões de pares, entre marcas próprias e licenciadas, sendo uma média de $12 \%$ destinada ao mercado externo. Do total produzido, aproximadamente $30 \%$ se refere à produção de calçados masculinos, $30 \%$, a calçados femininos e $40 \%$, a calçados infantis. A empresa detém por volta de $90 \%$ do mercado interno e $10 \%$ do mercado externo. A produção destina-se a mais de 60 países, sendo os principais mercados importadores: Estados Unidos, França, Itália, Alemanha, Inglaterra, Espanha, Argentina e Canadá.

A Empresa B ocupa o primeiro lugar no ranking do setor calçadista na América Latina e está entre as maiores do mundo, além de ser líder do segmento feminino na América Latina e do segmento esportivo no Brasil. Empresa do tipo S.A., sua produção é de calçados femininos, de couro e material sintético, e esportivos. As unidades produtivas encontram-se divididas entre os Estados do Rio Grande do Sul (três unidades), Bahia (uma unidade) e Sergipe (uma unidade). Sua produção diária é de cerca de 150 mil pares/ dia, totalizando 45 milhões pares/ano, e suas unidades produtivas somam mais de $150 \mathrm{mil}$ metros quadrados. Para tanto, emprega cerca de 14 mil trabalhadores diretamente e em torno de 
3,5 mil indiretamente. Desse volume de produção, $75 \%$ destina-se ao mercado interno e $25 \%$, ao mercado externo. A Empresa B exporta seus produtos, com marca própria, para mais de 70 países, destacando-se Estados Unidos (maior mercado consumidor), México, Chile e Bolívia.

A Empresa $\mathbf{C}$ tem capacidade instalada para produzir 50 mil pares/dia de calçados femininos, principalmente de couro, e de tênis, empregando cerca de 7.500 funcionários. Seu complexo industrial encontra-se dividido entre os Estados do Rio Grande do Sul (nove unidades) e Ceará (duas unidades). Do total produzido, $80 \%$ destina-se ao mercado internacional - Estados Unidos, Europa e América Latina - e 20\%, ao mercado interno. Seus produtos visam principalmente ao segmento feminino e de alta renda. O Nordeste é responsável por pedidos maiores, ou seja, produz maior quantidade de um único modelo de calçado a cada pedido, sendo toda a produção destinada ao mercado externo. $\mathrm{O}$ mercado interno brasileiro de alta renda é atendido pela produção gaúcha, responsável também pela produção de calçados para exportação e de tênis. Trata-se de uma empresa do tipo Ltda., com participação em atividades correlatas, como curtumes, lojas próprias, fazendas para produção de couro e empreendimentos mobiliários. Porém, é baixa a porcentagem de integração vertical. A Tabela 6 traz as principais informações sobre as empresas consideradas.
A realização de entrevistas semi-estruturadas e a avaliação de documentos com informações sobre as três empresas consideradas (A, B e C) tornam possível identificar as estratégias adotadas pelas mesmas no novo ambiente competitivo. Vale ressaltar que algumas estratégias são comuns a todas elas, decorrentes de características próprias de empresas do setor de calçados. Com a finalidade de facilitar a análise e a exposição dos resultados, as estratégias estão organizadas na Tabela 7 e são divididas em três grupos: estratégia tecnológica, de localização e reorganizadoras.

A seguir, serão discutidos os resultados dos três estudos de caso.

\section{Discussão dos resultados}

A análise das proposições consideradas neste estudo passa por três critérios possíveis de avaliação: confirmada, parcialmente confirmada ou rejeitada.

P1. "As empresas calçadistas foram afetadas, em graus diferenciados, pelo processo de abertura comercial e pela sobrevalorização cambial, de acordo com o segmento em que atuam."

Esta proposição foi confirmada. As três empresas consideradas neste estudo (A, B e C), por atuarem em segmentos diferentes, foram afetadas diferentemente pelo processo de abertura comercial e pela sobrevalorização cambial.

Tabela 6 - Características gerais das empresas consideradas.

\begin{tabular}{lccc}
\hline & Empresa A & Empresa B & Empresa C \\
\hline Principal produto & Calçados injetados & $\begin{array}{c}\text { Calçados femininos } \\
\text { de couro e tênis }\end{array}$ & $\begin{array}{c}\text { Calçados femininos } \\
\text { de couro e tênis }\end{array}$ \\
Pegmento de atuação & popular & Todos os segmentos & Alta renda \\
Número de funcionários (diretos) & 16.000 & 14.000 & 7.500 \\
Produção & 80 milhões de pares & 45 milhões de pares & 15 milhões de pares \\
$\%$ exportada & $12 \%$ & $25 \%$ & $80 \%$ \\
\hline
\end{tabular}

Fonte: Organizada pelos autores. 


\section{Tabela 7 - Conjunto de estratégias adotadas pelas empresas A, B e C no novo ambiente competitivo.}

\begin{tabular}{|c|c|c|c|}
\hline & Empresa A & Empresa B & Empresa C \\
\hline \multirow{11}{*}{ 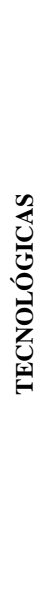 } & Informatização das atividades & Informatização das atividades & Informatização das atividades \\
\hline & $\begin{array}{l}\text { Investimentos anuais em máquinas e } \\
\text { equipamentos }\end{array}$ & Investimentos anuais em máquinas e equipamentos & $\begin{array}{l}\text { Investimentos anuais em máquinas e } \\
\text { equipamentos }\end{array}$ \\
\hline & Importação de máquinas e equipamentos & Importação de máquinas e equipamentos & Importação de máquinas e equipamentos \\
\hline & Investimentos em atividades de $\mathrm{P} \& \mathrm{D}$ & Investimentos em atividades de $\mathrm{P} \& \mathrm{D}$ & $\begin{array}{c}\text { Investimentos em atividades de P\&D para } \\
\text { produtos destinados principalmente ao } \\
\text { mercado interno }\end{array}$ \\
\hline & Investimentos em atividades de design no RS & $\begin{array}{l}\text { Investimentos em atividades de design e manutenção } \\
\text { de laboratórios de pesquisa no RS }\end{array}$ & $\begin{array}{l}\text { Investimentos em atividades de design no RS } \\
\text { para produtos destinados ao mercado interno }\end{array}$ \\
\hline & Organização da produção em células & Organização da produção em células & \\
\hline & & & $\begin{array}{c}\text { Produção em pequenos lotes, organizada em } \\
\text { esteiras }\end{array}$ \\
\hline & Criação e utilização das resinas de PU e PVC & & \\
\hline & $\begin{array}{l}\text { Utilização de "couro sintético" para } \\
\text { fabricação de calçados }\end{array}$ & & \\
\hline & Fabricação de calçados femininos de couro & & \\
\hline & Utilização da técnica de pintura de calçados & & \\
\hline \multirow{2}{*}{ 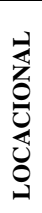 } & $\begin{array}{c}\text { Transferência de unidades de produção para } \\
\text { o Ceará }\end{array}$ & $\begin{array}{c}\text { Transferência de unidades de produção para a Bahia e } \\
\text { Sergipe }\end{array}$ & $\begin{array}{c}\text { Transferência das unidades de produção para } \\
\text { o Ceará }\end{array}$ \\
\hline & $\begin{array}{c}\text { Manutenção das atividades de administração, } \\
\text { criação e desenvolvimento de novos produtos } \\
\text { no RS }\end{array}$ & $\begin{array}{l}\text { Manutenção das atividades de administração, criação } \\
\text { e desenvolvimento de novos produtos no RS }\end{array}$ & $\begin{array}{c}\text { Manutenção das atividades de administração, } \\
\text { criação e desenvolvimento de novos } \\
\text { produtos no RS }\end{array}$ \\
\hline \multirow{17}{*}{ 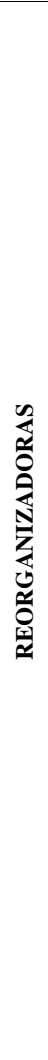 } & Importação de calçados de origem asiática & & \\
\hline & $\begin{array}{c}\text { Constante treinamento e aperfeiçoamento dos } \\
\text { funcionários }\end{array}$ & $\begin{array}{l}\text { Constante treinamento e aperfeiçoamento dos } \\
\text { funcionários, por meio de cursos de profissionalização }\end{array}$ & $\begin{array}{l}\text { Constante treinamento e aperfeiçoamento } \\
\text { dos funcionários }\end{array}$ \\
\hline & & Investimentos em benefícios para funcionários & $\begin{array}{l}\text { Investimentos em benefícios para } \\
\text { funcionários }\end{array}$ \\
\hline & $\begin{array}{l}\text { Aumento da terceirização, sem variação do } \\
\text { número de funcionários }\end{array}$ & & $\begin{array}{l}\text { Aumento da terceirização e redução do } \\
\text { número de funcionários }\end{array}$ \\
\hline & & $\begin{array}{l}\text { Redução da terceirização e aumento do número de } \\
\text { funcionários contratados }\end{array}$ & \\
\hline & $\begin{array}{l}\text { Participação em feiras nacionais e } \\
\text { internacionais }\end{array}$ & Participação em feiras nacionais e internacionais & $\begin{array}{l}\text { Participação em feiras nacionais e } \\
\text { internacionais }\end{array}$ \\
\hline & $\begin{array}{l}\text { Busca de conceituação e valorização da marca } \\
\text { dos produtos }\end{array}$ & $\begin{array}{c}\text { Busca de conceituação e valorização da marca dos } \\
\text { produtos }\end{array}$ & \\
\hline & $\begin{array}{l}\text { Interaçã com fornecedores de máquinas e } \\
\text { equipamentos }\end{array}$ & $\begin{array}{c}\text { Interação com fornecedores de máquinas e } \\
\text { equipamentos }\end{array}$ & \\
\hline & Estabelecimento de subsidiárias no exterior & $\begin{array}{l}\text { Estabelecimento de unidades de representação } \\
\text { comercial no exterior }\end{array}$ & $\begin{array}{l}\text { Estabelecimento de unidades de } \\
\text { representação comercial no exterior }\end{array}$ \\
\hline & & & $\begin{array}{c}\text { Implantação do Sistema de Gestão } \\
\text { Ambiental (SGA) e Certificação ISO } 14001\end{array}$ \\
\hline & Participação em central de negócios on-line & & \\
\hline & & Estrutura verticalizada & \\
\hline & Exposição de produtos em supermercados & & \\
\hline & & $\begin{array}{l}\text { Importação de couro dos EUA para produção de } \\
\text { calçados de alto valor agregado }\end{array}$ & $\begin{array}{l}\text { Importação de couro dos EUA para produção } \\
\text { de calçados para exportação }\end{array}$ \\
\hline & & Utilização do Sistema de Garantia da Qualidade & $\begin{array}{c}\text { Utilização do Sistema de Garantia da } \\
\text { Qualidade }\end{array}$ \\
\hline & & Implantação do Controle da Qualidade Total (TQC) & $\begin{array}{c}\text { Implantação do Programa de Qualidade } \\
\text { Total }\end{array}$ \\
\hline & & Adoção dos princípios do just-in-time & \\
\hline
\end{tabular}


A Empresa A foi mais fortemente afetada pelo processo de abertura comercial, uma vez que seus produtos passaram a concorrer com os produtos asiáticos, de maior qualidade e menores preços. A importação de calçados asiáticos foi facilitada pela sobrevalorização cambial, pela redução das tarifas de importação e pelo fato de o Brasil não contar com vantagens competitivas expressivas no segmento de injetados, em que atua a Empresa A. Reconhecida como uma estratégia de produção, a importação desses produtos foi a solução encontrada para que a empresa pudesse atuar no novo ambiente competitivo.

A Empresa B também foi afetada pelo processo de abertura comercial e sobrevalorização cambial, pois sua produção é, principalmente, de calçados femininos de couro destinados a todos os segmentos e voltada ao mercado interno. Assim, os calçados produzidos pela empresa passaram a concorrer com os de couro chineses e italianos. Os calçados italianos de couro gozaram de redução de custos, explicada pela adoção, por parte das empresas calçadistas italianas, da terceirização da produção em países que apresentavam menores custos de mão-de-obra. Entretanto, as importações de calçados femininos de couro não chegaram a representar uma participação de mercado relevante no Brasil, assim, seu efeito foi relativamente menor que aquele sentido pela Empresa A.

Já a Empresa C foi mais afetada pela sobrevalorização cambial, pois se caracteriza, principalmente, como produtora de calçados femininos de couro destinados ao segmento de alta renda e ao mercado externo. Desse modo, a sobrevalorização cambial encareceu as exportações, o que fez com que a empresa reduzisse suas margens, sob pena de perder mercado.

P2. "O novo ambiente competitivo exigiu das empresas a capacidade de adotar estratégias tecnológicas com o objetivo de ampliarem suas capacidades tecnológicas."

Essa proposição foi confirmada. A adoção de estratégias tecnológicas por parte das empresas analisadas abrangeu as atividades de pesquisa e desenvolvimento, o projeto do produto e os processos de fabricação e gestão da produção. Conforme pôde ser identificado na apresentação dos casos, algumas estratégias tecnológicas foram adotadas pelas três empresas.

Ainda, maior importância tem sido dada às atividades de pesquisa e desenvolvimento, por meio de investimentos anuais consideráveis nessas áreas, e às atividades de design. A Empresa C conta com visitas de designers internacionais para produção de calçados destinados ao mercado externo. Nesse sentido, a sofisticação das atividades de design, por parte das empresas analisadas, gerou notável elevação do conteúdo tecnológico dos produtos, conforme apontado por Garcia (1996).

P3. "A relocalização das unidades de produção para o Nordeste é importante estratégia de redução dos custos de produção adotada pelas empresas calçadistas, explicada principalmente pelo baixo custo da mão-de-obra e pelos incentivos fiscais. Essa estratégia é entendida como fundamental para sobrevivência no novo ambiente competitivo, sobretudo como meio de redução de custos."

Essa proposição foi confirmada. A estratégia de relocalização foi adotada pelas três empresas analisadas: A Empresa A transferiu para o Ceará nove unidades de produção, a Empresa B mantém uma unidade na Bahia e outra em Sergipe e a Empresa C mantém duas unidades de produção no Ceará. Vale ressaltar que as Empresas B e C ainda mantêm unidades de produção no Estado do Rio Grande do Sul: três e nove unidades, respectivamente. Como conseqüência, não há propriamente migração da indústria para o Nordeste, mas uma nova configuração espacial da produção, em que as atividades de maior conteúdo tecnológico e de conhecimento continuam se aproveitando de economias de aglomeração em seus pólos originais, nas regiões Sul e Sudeste do Brasil.

Porém, vale destacar que as atividades de administração, pesquisa e desenvolvimento de produtos, design e marketing continuam sendo desenvolvidas no Estado do Rio Grande do Sul. Foram transferidas apenas as atividades de pro- 
dução, uma vez que as empresas reforçam a dificuldade em encontrar na região Nordeste profissionais capacitados a desenvolver tais atividades.

P4. "A adoção de estratégias como a terceirização das atividades e a introdução de novos sistemas de produção surgiu em resposta ao novo ambiente competitivo. Os objetivos são reduzir os custos de produção e ganhar velocidade de resposta às modificações da demanda."

Essa proposição foi parcialmente confirmada. A estratégia de terceirização das atividades não foi adotada pelas três empresas analisadas. Apenas as Empresas A e $\mathbf{C}$ consideraram a terceirização uma estratégia de redução dos custos. A Empresa B optou pela elevação do número de trabalhadores contratados e pela redução da terceirização, em função dos riscos trabalhistas. Adicionalmente, dada à elevada escala em que opera a Empresa B, sua propensão à integração vertical é maior, uma vez que pode se apropriar de ganhos de escala em uma produção voltada às próprias necessidades (Williamson, 1996).

Em parte, isso se deve à transferência de unidades de produção para o Nordeste, a qual não resultou em nova aglomeração de empresas. Conhecidas como clusters, de acordo com Garcia (2001), as aglomerações criam externalidades positivas, como acesso privilegiado a serviços e tarefas a custos reduzidos, a partir do apoio do setor público local. O processo de circulação de informações e conhecimentos, por meio de canais próprios de comunicação e de fontes específicas de informação, também é facilitado. Ainda, há a formação das "indústrias correlatas de apoio" (Porter, 1990). Os fornecedores de máquinas e equipamentos, peças e serviços especializados são atraídos a estabelecer unidades nas aglomerações industriais, o que possibilita a geração de economias externas.

Porém, considerando que a lógica da política de incentivos fiscais é a de espalhar os investimentos pelo maior número possível de municípios, as empresas não constituíram os chamados clusters no Nordeste. Dessa forma, os ganhos de terceirização de atividades para firmas de menor porte, derivados da coordenação de redes de produção, ficam limitados nessas regiões. É importante notar, entretanto, que a redução da terceirização por parte da Empresa B deu-se também no Vale dos Sinos, principal aglomeração de empresas calçadistas do Brasil, o que indica uma opção organizacional que independe do fato de contar ou não com as economias de aglomeração.

Quanto aos sistemas de produção, as empresas analisadas também apresentam divergências. As Empresas A e B utilizam a produção em células, enquanto a Empresa $\mathbf{C}$ organiza a produção em esteiras. A organização em células, como parte dos princípios do just-in-time, é reconhecida como meio de fornecer maior flexibilidade e velocidade às trocas de produto e processo. As células são organizadas de acordo com as modificações da demanda, o que também melhora a capacitação em processo de fabricação. Assim, as Empresas A e B reconhecem nesse método de produção um meio de ganhar velocidade de resposta diante das modificações da demanda e da redução de custos.

A Empresa $\mathbf{C}$ reconhece as mesmas possibilidades, ganhos em velocidade e redução de custos, pela adoção da organização da produção em esteiras. Por se tratar de um processo de movimentação mecanizado, a velocidade é alcançada pela adoção do sistema de "Troca Rápida de Ferramentas". Ainda, a vantagem em custos é explicada pela maior produtividade alcançada pela organização em esteiras, uma vez que a movimentação manual (observada na produção em células) é considerada improdutiva pela empresa.

Essa diferença de casos pode ser atribuída ao distinto perfil da demanda. Enquanto as Empresas A e B destinam a parte mais relevante de sua produção ao mercado interno, as exportações absorvem $80 \%$ da produção da Empresa C. Normalmente, as vendas ao mercado externo são feitas por meio de contratos a termo, para entrega futura da mercadoria, o que reduz os riscos de flutuação da demanda. Ademais, a exemplo da maioria das empresas exportadoras brasileiras, 
parte da produção da Empresa C é encomendada a partir de designs fornecidos pelo comprador, o que mais uma vez atenua os riscos de flutuação de demanda. Esses fatos devem explicar a razão de a produção em esteira ser considerada satisfatória para os problemas de produção da empresa.

Confrontando, por intermédio de critérios de interpretação, os dados obtidos na pesquisa de campo com as proposições formuladas, verificamos que três proposições foram confirmadas e uma foi parcialmente confirmada.

\section{Considerações finais}

A partir dos anos 90, o novo ambiente competitivo tem sido marcado por importantes mudanças institucionais e macroeconômicas. Como mudanças institucionais destacam-se o processo de abertura comercial e a Constituição de 1988, responsáveis por importantes modificações nas regras do comércio e na atuação dos Estados brasileiros quanto ao desenvolvimento industrial, respectivamente. Pararelamente, a sobrevalorização do real, entre 1994 e 1998, dificultou a sobrevivência de empresas de calçados voltadas à exportação e facilitou a entrada de produtos importados, notadamente nos segmentos de tênis e injetados. Assim, a preocupação com qualidade, preço e design, entre outras, ganhou papel de destaque como meio de sobrevivência no novo ambiente competitivo.

A análise do caso de três grandes empresas pertencentes ao setor calçadista mostra que essas empresas foram afetadas, em diferentes graus, pelo processo de abertura comercial e pela sobrevalorização cambial. A relocalização das unidades de produção foi observada nas três empresas, que mantêm unidades produtivas no Nordeste, e o principal impacto foi a redução de custos. Finalmente, foram observadas divergências na adoção da terceirização de atividades de produção pelas empresas calçadistas analisadas neste estudo.

Por se tratar de apenas três casos, todos de empresas de grande porte, é possível que outros tipos de estratégia sejam representativos do conjunto das empresas de calçado brasileiras. Particularmente, há indícios de que o processo de relocalização afetou sobretudo as grandes empresas, em decorrência de sua posição mais vantajosa para captar benefícios fiscais. Seria, portanto, desejável a realização de novos estudos que investiguem as estratégias, implementadas no mesmo período, de empresas de menor porte para fazer frente ao novo ambiente competitivo.

\section{Referências Bibliográficas}

ALVES FILHO, A. G. Estratégia tecnológica, desempenho e mudança: estudos de caso em empresas da indústria calçadista. 1991. Tese (Doutorado) Escola Politécnica, Universidade de São Paulo, São Paulo.

AZEVEDO, P. F. Diagnóstico da cadeia produtiva de couro e calçados. 2001. Mimeografado.

AZEVEDO, P. F.; FRANCISCHINI, A. S. N. Comportamento tecnológico na indústria de calçados. UNESP, 2002. Relatório do Projeto "Comportamento Tecnológico das Empresas. GEEIN Grupo de Estudos em Economia Industrial”.

AZEVEDO, P. F.; TONETO Jr., R. Determinantes da relocalização do emprego formal no Brasil: evidências a partir de setores selecionados. Pesquisa e Planejamento Econômico, IPEA, dez. 2001.
BNDES - Banco Nacional de Desenvolvimento Econômico e Social. Panorama da indústria mundial de calçados, com ênfase na América Latina. 2001.

COUTINHO, L. G. (Coord.). Estudos de competitividade da indústria brasileira. Campinas: Ministério da Ciência e Tecnologia, 1993.

GARCIA, R. C. Aglomerações setoriais ou distritos industriais: um estudo das indústrias têxtil e de calçados no Brasil. 1996. Dissertação (Mestrado) - Instituto de Economia, Universidade Estadual de Campinas, Campinas.

- Vantagens competitivas de empresas em aglomerações industriais: um estudo aplicado à indústria brasileira de calçados e sua inserção nas cadeias produtivas globais. 2001. Tese (Doutorado) - Instituto de Economia, Universidade Estadual de Campinas, Campinas. 
GORINI, A. P. F. (Org.). Informes setoriais: o setor de calçados no Brasil. BNDES, maio 1998.

GORINI, A. P. F.; SIQUEIRA, S. H. G. Complexo coureiro-calçadista. Rio de Janeiro: BNDES, 1998. (Relatório Setorial.)

GREMAUD, A. P.; VASCONCELLOS, M. A. S.; TONETO Jr., R. Economia brasileira contemporânea. 4. ed. São Paulo: Atlas, 2002. 626 p.

MINISTÉRIO DO DESENVOLVIMENTO, INDÚSTRIA E COMÉRCIO EXTERIOR. Ações setoriais para o aumento da competitividade da indústria brasileira: couro e calçados. 2002.
NORTH, D. C. Custos de transação, instituições e desempenho econômico. Rio de Janeiro: Instituto Liberal, jun. 1994. 38 p.

PORTER, M. E. The competitive advantage of nations. Harvard University Free Press, 1990. p. 855.

SLACK, N.; CHAMBERS, S.; HARLAND, C.; HARRISON, A.; JOHNSTON, R. Administração da produção. São Paulo: Atlas, 1997.

WILLIAMSON, O. The mechanisms of governance. New York: Oxford University Press, 1996.

\title{
FOOTWEAR INDUSTRY STRATEGIES FOR THE NEW COMPETITION ENVIRONMENT: A THREE CASE STUDY ANALYSIS
}

\begin{abstract}
The competitive environment during the 1990's - with trade liberalization, the new rules set by the Brazilian Constitution of 1988, exchange rate appreciation and changes in the international competitionhad distinct effects on each Brazilian industry. This article analyzes the technological, locacional and organizational strategies in three footwear firms. Based in four propositions, we evaluate the three types of strategies and how the differ in accordance with firm characteristics.
\end{abstract}

Key words: footwear, competition environment, strategy. 